\title{
Is It Possible to Make a Diagnosis in an Ambulance?
}

\author{
Masahiko OKADA, MD and Mihoko OKaDA, MS
}

\begin{abstract}
We have developed a computer method to make a diagnosis for an emergency patient using the data reported by a person who has no technical knowledge of medicine such as a member of the public or an ambulance attendant. The speedy instruction will be made possible by a computer diagnosis, by which an ambulance attendant could deliver the patient expeditiously to the most appropriate medical facility. We first conducted a survey by means of questionnaire and investigated the relationship between the patients' data and diagnosis of medical doctors. It was shown that fairly accurate diagnosis could be made on treatment, hospitalization, an appropriate medical department and need of urgent care, using simple information like age, sex, cause of illness or injury, and 15 symptoms which trained laymen could judge. Accuracy of the diagnosis was $79.3 \%$ on the average.
\end{abstract}

Key Words: $\quad$ Computer diagnosis, Data reduction, Emergency patient, Prehospital care

Good and speedy emergency medical service is an essential part of our efforts toward reduction of mortality rate of patients with serious illness or injury. Frey et al. pointed out a possibility of decreasing the number of traffic trauma deaths by organizing a specially trained medical rescue squad and striving for extension and improvement of emergency facilities ${ }^{1)}$. Later, Waters and Wells reported significant decreases noted in death rates caused by automobile crash in the city of Jacksonville, Florida ${ }^{2)}$ through the improvement of the emergency medical care system. In Jacksonville, it was reported that the patient was treated promptly on the spot of accident by highly trained technicians aided by radioed physician's advice.

Generally speaking, however, it is practically impossible to expect the physicians to be on 24 hours stand-by for an emergency case, not to mention areas of low population density, even in urban areas with possible exceptions. In this study, we examined the possibility of making a diagnosis using the computer in the absence of physician. Although several papers have been published on the physical layout of efficient hospitals and mathematical analysis of patient's travel cost in view of the emergency service improvement ${ }^{3,4)}$, little has been discussed on the introduction of computer diagnosis into a regional health care system, where members of the public in need of urgent help may be assisted by telephone and may get adequate advice without the presence of physicians. Data items used in this study included patient's age, sex, cause of illness or injury and those symptoms which non-medical staff can discern, and decisions were made on treatment, necessity of hospitalization, department of medical specialty and need of urgent care.

\section{MATERIALS AND METHODS}

\section{Data Acquisition}

A questionnaire was set out twice in Niigata Prefecture, Japan in relation to emergency medical services, first in summer, July 1977 and second in winter, February 1978. Questionnaires were distributed to all 1,334 medical institutions in the prefecture to collect information on every patient who had visited the institutions during night time and holidays for a specified one week period. Replies submitted to the questionnaire covered 20,369 patients. (The survey was sponsored by

From the Division of Medical Informatics, Niigata University Hospital, and the Faculty of General Education, Niigata University, Niigata.

Received for publication September 10, 1982.

Reprint request to: Masahiko Okada, MD, The division of Medical Informatics, Niigata University Hospital, Asahimachi 1, Niigata, 951, Japan. 
Table 1. Data Items Used in Questionnaire Descriptor Variables

\begin{tabular}{|c|c|c|}
\hline \multicolumn{3}{|l|}{ AGE } \\
\hline SEX & 1. Male & 2. Female \\
\hline \multirow[t]{3}{*}{ CAUSE } & 1. Disease & 2. Traffic accident \\
\hline & 3. Trauma & 4. Poisoning \\
\hline & 5. Selfwrong & 6. Foreign body swallowed \\
\hline \multirow[t]{12}{*}{ SYMPTOMS } & 1. Severe headache & 2. Chest pain \\
\hline & 3. Abdominal pain & 4. Clouding of consciousness \\
\hline & 5. Dizziness \& Vertigo & 6. Convulsion \\
\hline & 7. Paralysis & 8. Fever \\
\hline & 9. Cyanosis & 10. Arrhythmia \\
\hline & 11. Tachycardia & 12. Bradycardia \\
\hline & 13. Massive bleeding & 14. Anemia \\
\hline & 15. Dyspnea & 16. Cough \\
\hline & 17. Stridor & 18. Hemoptysis \\
\hline & 19. Nausea & 20. Vomiting \\
\hline & 21. Hematemesis & 22. Bloody stool \\
\hline & 23. Diarrhea & 24. Urinary retention \\
\hline
\end{tabular}

Niigata Prefecture Medical Doctors' Association.) The data items included in the questionnaire are listed in Table 1 and 2. As to the question on symptoms, only those symptoms which could be checked by nonphysicians were included. This has been done with the consideration in mind that an ambulance attendant might report on the patients' condition for computer diagnosis making use of such a list of symptoms ${ }^{5}$.

In judging the urgency of the case (Table 2), questionnaire participants were requested to mark "yes" if the patient needed respiratory or circulatory intensive care and/or if he or she might have severe sequelae when he or she was left untreated. In our study on computer diagnosis, the total number of patients accounted for was 16,793 excluding non-emergency cases and incomplete replies.

\section{Decision Rule}

We investigated a possibility of making an appropriate decision on items shown in Table 2 using the data given in Table 1 . The decision algorithm was based in principle on Bayes' theo$\mathrm{rem}^{6}$, which is widely used in computer diagnosis, with slight modification. Details of the method are given in the appendix. The probability $\mathrm{P}(\mathrm{Si}$ $\mathrm{D} \alpha)$ of a symptom $\mathrm{Si}$ occurring in a class $\mathrm{D} \alpha$ was calculated using the data obtained from the first
Table 2. Data Items Used in Questionnaire Diagnostic Category

\begin{tabular}{lll}
\hline TREATMENT & 1. Surgical & 2. Internal \\
ADMISSION & 1. Not admitted & 2. Admitted \\
DEPARTMENT & 1. ICU & 2. Respiratory* \\
& 3. Digestive* & 4. Circulatory* \\
& 5. Neurological* & 6. Others* \\
& 7. Pediatrics & 8. Neurosurgery \\
& 9. Chest surgery & 10. General surgery \\
& 11. Urology & 12. Gynecology \& obstetrics \\
& 13. Orthopedics & 14. Ophthalmology \\
& 15. Otorhinolaryngology & 16. Psychiatrics \\
& 17. Dermatology & 18. Radiology \\
EMERGENCY & 19. Anesthesiology & 20. Dentistry \\
\hline
\end{tabular}

* A division of internal medicine.

Table 3. Decision Rules Applied to Computer Diagnosis AGE;

If AGE $\geqq 15$, exclude Pediatrics from DEPARTMENT.

If AGE $\leqq 9$, and CAUSE is Disease, decide on Pediatrics as DEPARTMENT.

SEX;

If SEX is Male, exclude Gynecology from DEPARTMENT. CAUSE;

If CAUSE is Traffic accident or Trauma, exclude all Internal Medicines and Pediatrics from DEPARTMENT. If CAUSE is Traffic accident or Trauma, decide on Surgical as TREATMENT.

questionnaire. As to the decision making regarding department, 'ICU' through 'Gynecology' in Table 2 were the objects of computer diagnosis, while 'Orthopedics' to 'Dentistry' were left to the judgement of ambulance attendants. The decision rules shown in Table 3 were incorporated into the diagnostic process.

\section{Data Reduction}

An ambulance attendant does not usually have much time to spend checking a long list of symptoms when he is busy en route to the hospital. Therefore, it was desired to shorten the checking list, maintaining the percentage of correct diagnose as high as possible. Entropy weighted with similarity ${ }^{7)}$ (will be called weighted entropy hereafter) has been used successfully for elimination of redundant data items in the differential diagnosis. We employed the method as a measure for 
relative usefulness of individual symptoms in the present diagnostic system.

\section{RESULTS}

The diagnostic goals consist of four items, that is, department, admission, treatment, and urgency. The first step in the emergency service is to determine which department of the medicine is most suitable for the patient. We evaluated symptoms in view of their significance for making a decision regarding the department.

Weighted entropy $\mathrm{H}(\mathrm{Si})$ was calculated for each of 24 symptoms against 12 departments. Table 4 shows a list of symptoms in order of the weighted entropy. The smaller the entropy is, the more significant considered is a given symptom.

Symptoms were eliminated step by step (starting from the bottom of Table 4) and changes in the percentage of correct diagnosis were examined.

Table 4. Weighted Entropy $\mathrm{H}(\mathrm{Si})$ of Symptoms

\begin{tabular}{|c|c|c|}
\hline \multicolumn{2}{|c|}{ SYMPTOMS Si } & \multirow{2}{*}{$\frac{\mathrm{H}(\mathrm{Si})}{0.0000}$} \\
\hline S18 & Hemoptysis & \\
\hline S24 & Urinary retension & 0.7077 \\
\hline $\mathrm{S} 12$ & Bradycardia & 0.7125 \\
\hline $\mathrm{S} 21$ & Hematemesis & 0.7802 \\
\hline S09 & Cyanosis & 0.8110 \\
\hline S02 & Chest pain & 0.9049 \\
\hline S17 & Stridor & 0.9698 \\
\hline S10 & Arrhythmia & 0.9804 \\
\hline $\mathrm{S} 13$ & Massive bleeding & 1.0803 \\
\hline $\mathrm{S} 23$ & Diarrhea & 1.0899 \\
\hline $\mathrm{S} 22$ & Bloody stool & 1.2272 \\
\hline S07 & Paralysis & 1.3111 \\
\hline $\mathrm{S} 16$ & Cough & 1.4021 \\
\hline S15 & Dyspnea & 1.4627 \\
\hline S04 & Clouding of consciousness & 1.4942 \\
\hline $\mathrm{S} 11$ & Tachycardia & 1.5254 \\
\hline S03 & Abdominal pain & 1.5357 \\
\hline S05 & Dizziness \& Vertigo & 1.6476 \\
\hline S08 & Fever & 1.6591 \\
\hline S06 & Convulsion & 1.6877 \\
\hline S20 & Vomiting & 1.9557 \\
\hline S14 & Anemia & 2.0262 \\
\hline S01 & Severe headache & 2.0529 \\
\hline S19 & Nausea & 2.0926 \\
\hline
\end{tabular}

Jap J Med Vol 22, No 1 (January, 1983)
Table 5. Changes in Percentage of Correct Diagnosis by Data Reductions

\begin{tabular}{lcccc}
\hline & \multicolumn{4}{c}{ No. of Selected Symptoms } \\
\cline { 2 - 5 } & 24 & 20 & 15 & 10 \\
\hline TREATMENT & $91.0 \%$ & $91.5 \%$ & $92.7 \%$ & $92.7 \%$ \\
ADMISSION & $74.5 \%$ & $69.7 \%$ & $74.3 \%$ & $69.3 \%$ \\
DEPARTMENT & $73.2 \%$ & $72.3 \%$ & $65.3 \%$ & $62.8 \%$ \\
EMERGENCY & $71.0 \%$ & $70.1 \%$ & $77.6 \%$ & $74.1 \%$ \\
& & & & \\
AVERAGE & $77.4 \%$ & $75.9 \%$ & $77.5 \%$ & $74.7 \%$ \\
\hline
\end{tabular}

The elimination procedure was repeated several times, reducing the number of symptoms by four to five at a time. Changes in the percentage of correct diagnosis were also examined as to treatment, admission, and urgency. As a result, the diagnoses based on 15 symptoms yielded relatively high percentage in spite of small quantity of available information (Table 5). Despite the fact that the symptoms were primarily selected for the diagnostic decision for an appropriate department, they performed as well in decision making regarding treatment, admission, and urgency. It was, therefore, decided not to prepare separate lists of basic symptoms for each goal.

As described previously, the questionnaire was conducted twice with a six months' interval, and the probability of a symptom occurring in an individual category $(\mathrm{P}(\mathrm{Si} \mid \mathrm{D} \alpha))$ was calculated using the data obtained at the first time (which covered

Table 6. Percentages of Correct Diagnoses with External Data

\begin{tabular}{lc}
\hline & $\begin{array}{c}\text { Percentages of } \\
\text { Correct Diagnoses }\end{array}$ \\
\hline TREATMENT & $94.3 \%$ \\
ADMISSION & $77.7 \%$ \\
DEPARTMENT & $62.8 \%$ \\
EMERGENCY & $82.3 \%$ \\
AVERAGE & $79.3 \%$ \\
\hline
\end{tabular}


10,637 patients). Also, the experiments described so far were carried out using the same set of data. In order to evaluate the validity of the method developed, the percentage of correct diagnosis was computed on the data of 6,156 patients acquired at the second time, using the same 15 symptoms. The results were satisfactory with the average percentage of $79.3 \%$ being correct diagnoses among the four goals as shown in Table 6 .

\section{DISCUSSION}

Most of the articles appeared in the computerdiagnosis literature reported high performance of over $90 \%$ correct diagnoses. Our method achieved ultimately $79.3 \%$, which is not very high in comparison. This can be attributed to the fact that the data we used were not those which were collected especially to make the study on computer diagnosis, not all that were available or all that were considered useful. In our developed method, a diagnosis is made using only those data items which are simple enough for non-medical staff like an ambulance attendant to check out without the presence of a physician. It has been disclosed by the recent survey that mere $65.1 \%$ of the patients were seen at the right department on their first visits. Viewed from this angle, we might say that the performance was satisfactory.

One of the difficulties in the application of the Bayes' theorem to the computer diagnosis is invalidity of independence assumption ${ }^{8,9)}$ on which the calculation of conditional probabilities is based. Symptoms are often interelated to each other, making the assumption fail. The failure of the assumption will only lead to the high rate of misclassification.

In order to solve this problem Gustafson et al. $^{10)}$ and Norusis and Jacquez ${ }^{11)}$ proposed the cluster model by which the data were classified into conditionally independent complexes. Fryback proposed the method of a first order approximation where conditional independence could partially be exploited ${ }^{12)}$. Weighted entropy employed in the present study works good against this problem of independency. Large weighted entropy indicates not only that such symptoms are less significant as information but also that they contain redundant information which can be derived from other symptoms. Hence elimination of such symptoms will contribute to prevent the degradation of performance caused by interdependency of symptoms ${ }^{7}$. As shown in Table 5, as we reduce the checking items little by little, correctness goes up temporarily, which seems to support our standpoint.

At present moment, emergency patients are being delivered to the nearest medical facilities regardless of specialties and capacities without going through the procedure that we explained in the previous chapter. Under these circumstances, we cannot always expect that the patient is given the treatment best suited to his conditions. The computer diagnosis discussed in this paper will make a contribution to the development and the improvement of the regional health care system.

\section{CONCLUSION}

A computer method has been developed to make a speedy diagnostic decision on an emergency patient based on the data reported by nonmedical personnel. It was shown that treatment, hospitalization, appropriate department and need for urgent care could be decided using data items such as age, sex, cause of illness or injury, and 15 symptoms which a trained layman could pick up. The method is meant to let an ambulance attendant know to which hospital he should take the patient. The performance of the method was on the average $79.3 \%$ in correct diagnosis. The method incorporated in an emergency medical care system would serve as a guide to an ambulance attendant in accomplishing his job in a rush situation unaided by a physician.

Complementary copies of the list of probabilities for symptoms occurrences $\mathrm{P}(\mathrm{Si} \mid \mathrm{D} \alpha)$ are available at the authors on request.

ACKNOWLEDGEMENTS: The authors wish to thank Ms. Keiko Yasuhara and Ms. Ryuko Sato for preparing the manuscript.

\section{APPENDIX}

In applying the Bayes' conditional probability to computer diagnosis, the following equation is generally used; 


$$
\begin{aligned}
\mathrm{P}(\mathrm{D} \alpha \mid \underline{\mathbf{S}}) & =\frac{\mathrm{P}(\mathrm{D} \alpha) \prod_{\mathrm{i}=1}^{\mathrm{m}} \mathrm{P}(\mathrm{Si} \mid \mathrm{D} \alpha)^{\mathrm{ki}} \cdot\left(1-\mathrm{P}(\mathrm{Si} \mid \mathrm{D} \alpha)^{1-\mathrm{ki}}\right.}{\sum_{\alpha=1}^{\mathrm{n}}\left[\mathrm{P}(\mathrm{D} \alpha) \prod_{\mathrm{i}=1}^{\mathrm{m}} \mathrm{P}(\mathrm{Si} \mid \mathrm{D} \alpha)^{\mathrm{ki}} \cdot(1-\mathrm{P}(\mathrm{Si} \mid \mathrm{D} \alpha))^{1-\mathrm{ki}}\right]},(1) \\
\alpha & =1,2, \ldots \ldots, \mathrm{n},
\end{aligned}
$$

where $\mathrm{P}(\mathrm{D} \alpha \mid \underline{\mathbf{S}})$ denotes the posterior probability that the disease is $\mathrm{D} \alpha$ given the patient's data $\mathrm{S}$, and $\mathrm{P}(\mathrm{Si} \mid \mathrm{D} \alpha)$ denotes the conditional probability of a symptom $\mathrm{Si}$ occurring in the disease $\mathrm{D} \alpha$, and ki takes 1 when Si exists and 0 when it does not.

Since the denominator in the equation (1) is common to all $\mathrm{D} \alpha$, only the numerator is required in this study. In order to prevent significant computational errors, we took logarithm of both sides of equation (1).

As to age, sex, and cause of illness, the probabilities were estimated by relative frequencies. Let $x_{1}$ be the variable representing age and $f_{1}$ be its frequency function. $\mathrm{x}_{1}$ takes the values 1,2 , $\ldots \ldots, 20$ representing age intervals (ages $0-99$ were divided into 20 intervals by every 5 years). $f_{1}\left(x_{1}\right)$ was calculated by dividing the number of patients within each interval by the total number of patients. Let $\mathrm{x}_{2}$ and $\mathrm{x}_{3}$ be the variables representing sex and cause of illness, and let $f_{2}$ and $f_{3}$ be the respective frequency functions. (All the causes are mutually exclusive.)

In the end, the following equation was established for use in the computer diagnosis;

$$
\begin{aligned}
& \operatorname{lnP}(D \alpha \mid \underline{\mathbf{S}})=1 \mathrm{nf}_{1}\left(\mathrm{x}_{1}\right)+1 \mathrm{nf}_{2}\left(\mathrm{x}_{2}\right)+1 \mathrm{nf}_{3}\left(\mathrm{x}_{3}\right)+ \\
& \sum_{\mathrm{i}=1}^{\mathrm{m}}\left[\ln \mathrm{P}(\mathrm{Si} \mid \mathrm{D} \alpha)^{\mathrm{ki}}+\right. \\
& \ln (1-\mathrm{P}(\mathrm{Si} \mid \mathrm{D} \alpha))^{1-\mathrm{ki}} \text {, }
\end{aligned}
$$

where $\mathrm{x}_{1} \in[1,2, \ldots \ldots, 20], \mathrm{x}_{2} \in[1,2], \mathrm{x}_{3} \in[1$, $2, \ldots, 6,6]$.

\section{REFERENCES}

1) Frey CF, Heulke DF and Gikas PW: Resuscitation and survival in motor vehicle accidents. $J$ Trauma 9: 292, 1969.

2) Water JM Jr and Wells CH: The effects of a modern emergency medical care system in reducing automobile crash deaths. J Trauma 13: 645, 1973.

3) Dökmeci VF : A quantitative model to plan regional health facility systems. Management Science 24: $411,1977$.

4) Varaiya P, Schweizer U and Hartwick J: A class of markovian problems related to the districting problem for urban emergency services. Ricerch Di Automatica 8: 1, 1977.

5) Ogawa $M$ and Sugimoto $T$ : Rating severity of the injured by ambulance attendants: Field research of trauma index. J Trauma 14: 934, 1974.

6) Waner HR, Wooley FR and Kane RL: Computer assisted instruction for teaching clinical decisionmaking. Comput Biomed Res 7: 564, 1974.

7) Okada M: A method for clinical data reduction based on "weighted entropy". IEEE Trans Biomed Eng BME-25: 462, 1978.

8) Norusis MJ and Jacquez JA: Diagnosis. I. symptom nonindependence in mathematical models for diagnosis. Comput Biomed Res 8: 156, 1975.

9) Starmer CF and Lee KL: A mathematical approach to medical decisions: Application of Bayes' rule to a mixture of continuous and discrete clinical variables. Comput Biomed Res 9: 531, 1976.

10) Gustafson DH, Kestly JJ, Ludke RL, et al: Probabilistic information processing: Implementation and evaluation of a semi-PIP diagnostic system. Comput Biomed Res 6: 355, 1973.

11) Norusis MJ and Jacquez JA: Diagnosis. II. diagnostic models based on attribute clusters: A proposal and comparisons. Comput Biomed Res 8: 173, 1975.

12) Fryback DG: Bayes' theorem and conditional nonindependence of data in medical diagnosis. Comput Biomed Res 11: 423, 1978. 